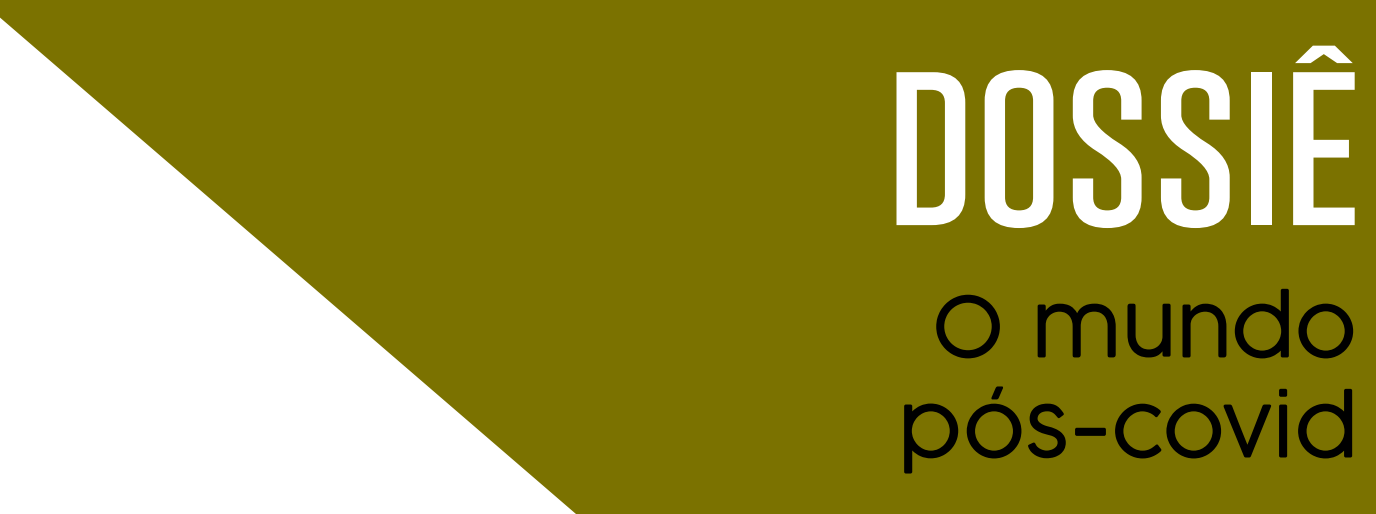

Organizadores:

Ilka Bichara e Nilson Weisheimer

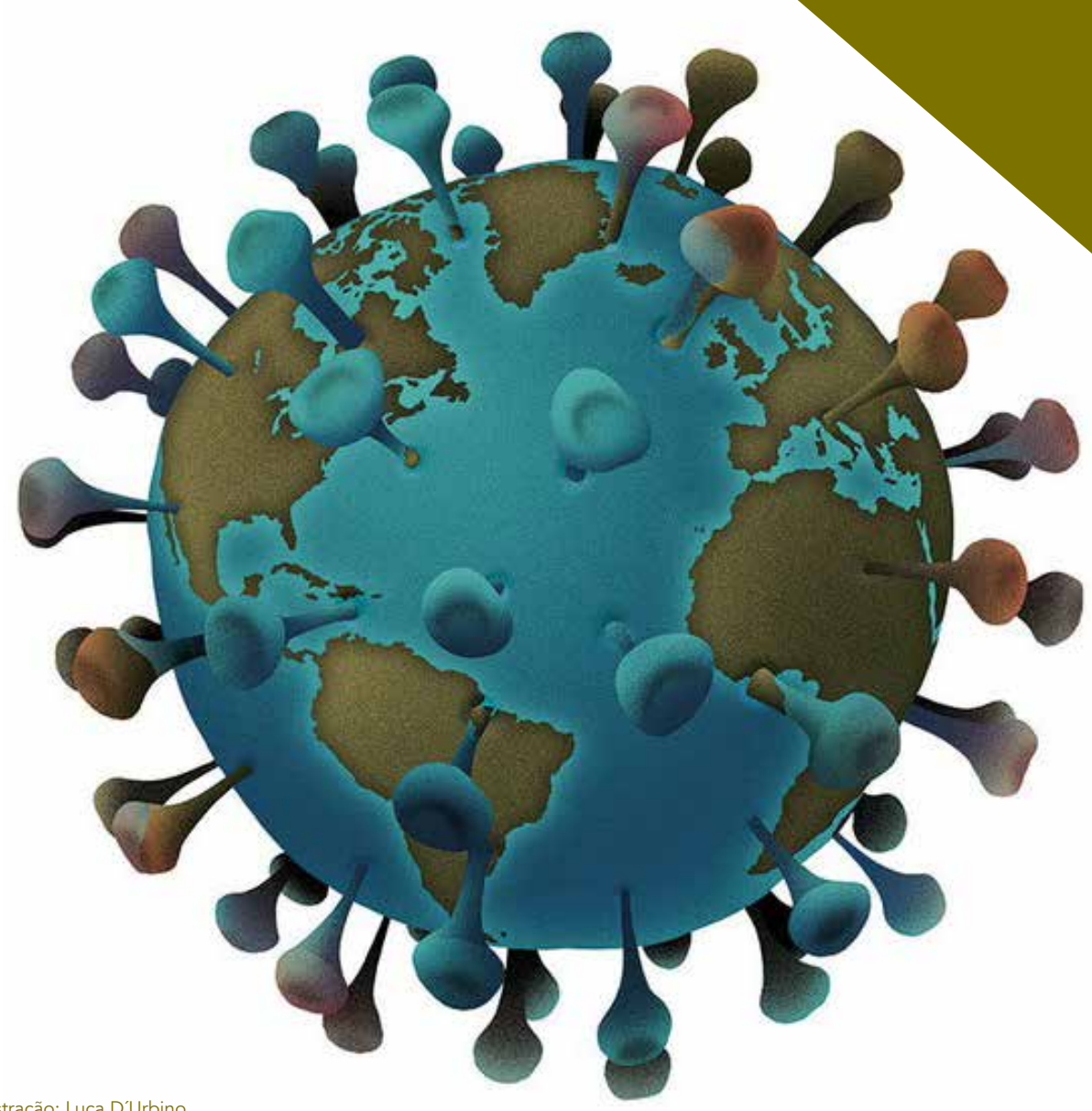

Ilustração: Luca D’Urbino

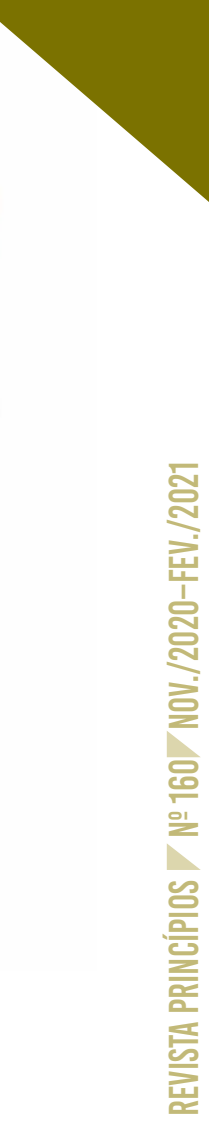

$\underline{7}$ 


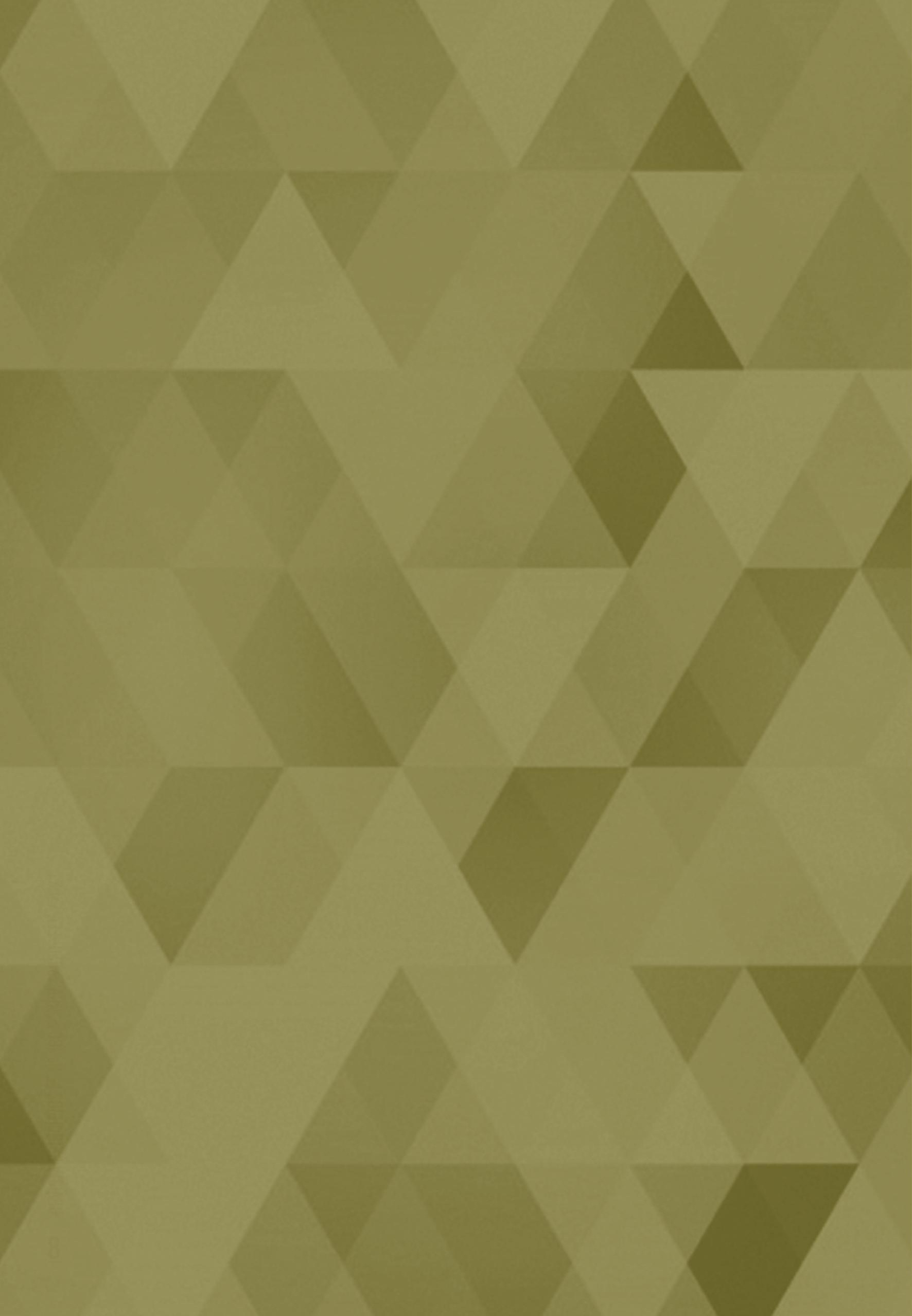




\section{China versus Estados Unidos na crise da pandemia: governança e politica confrontam desafios sistêmicos}

china versus US in the Pandemic crisis: covernance and Politics confronting systemic challenges

\section{DiC LO* Yuning shi**}

DOI: https://doi.org/10.4322/principios.2675-6609.2020.160.001

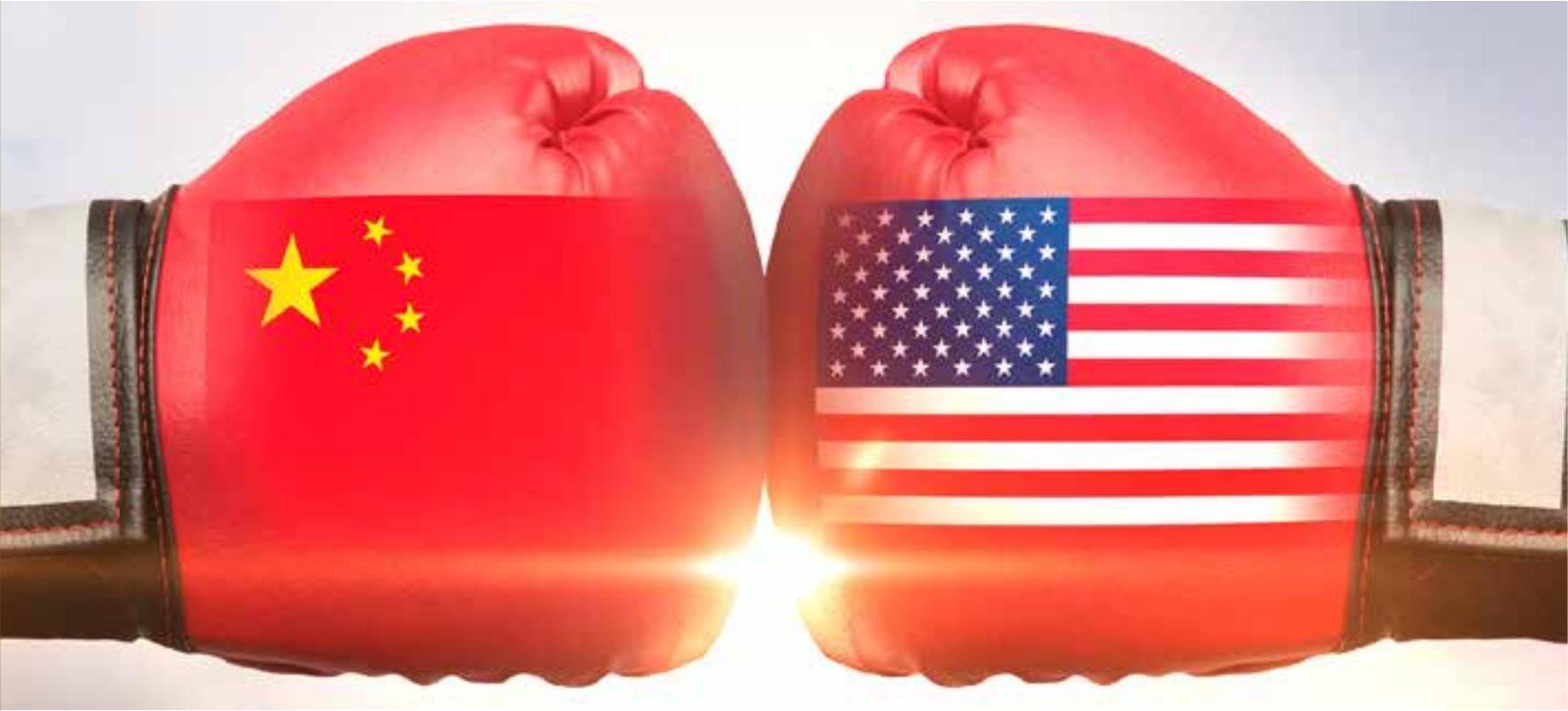




\section{RESUMO}

Por conta de sua natureza peculiar como desafio sistêmico, o controle da crise de covid-ı exige ações rápidas e fortes. Parece que a China adotou um "modelo firme", enquanto as medidas erráticas dos Estados Unidos formaram um "modelo frouxo". Este artigo busca caracterizar e examinar os dois modelos pela perspectiva das estruturas de governança e das capacidades corretivas dos dois diferentes sistemas políticos. A exposição usa o quadro teórico da "saída, voz e lealdade" desenvolvido por Albert Hirschman e rejeita a ideologia hegemônica da dicotomia "democracia liberal contra autoritarismo".

Palavras-chave: Coronavírus. Desafios sistêmicos. Meritocracia. Democracias. Autoritarismo.

\section{ABSTRACT}

Because of its peculiar nature as a systemic challenge, the control of the covid-I9 crisis requires strong and rapid actions. It appears that China has employed a "tough model" whereas the erratic measures of the US have formed a "loose model". This paper seeks to characterize and assess the two models from the perspective of the governance structures and the corrective capabilities of the two different political establishments. The exposition draws on the framework of "exit, voice, and loyalty" developed by Albert Hirschman, and rejects the hegemonic ideology of the "liberal democracy versus authoritarianism" dichotomy.

Keywords: Coronavirus. Systemic challenges. Meritocracy. Democracies. Authoritarianism. 


\section{INTRODUÇ̃̃o}

Na primeira fase da covid-I9, quando a epidemia estava circunscrita à China, comentaristas internacionais foram rápidos em afirmar que a política era o problema. Essa afirmação veio não apenas de jornalistas ou políticos, mas também de acadêmicos. Quase como um reflexo, o aforismo do economista e filósofo Amartya Sen, "[catástrofes] estão fortemente relacionadas à ausência de liberdade de informação e crítica" (SEN, I989), é, consciente ou inconscientemente, adotado como o fundamento intelectual da afirmação.

Essa afirmação, ao estilo de Sen, pode ser questionada por vários ângulos. É discutível se o que realmente aconteceu na China durante o surto inicial da epidemia pode ser adequadamente apreendido por essa afirmação. Mais importante, o espalhamento subsequente da epidemia pelo mundo todo parecia ser anômalo para a afirmação. Países frequentemente chamados de "democracias liberais" não se saíram bem. Os Estados Unidos da América, em particular, se saíram de forma miserável tanto no combate à epidemia quanto em termos do custo social e econômico resultante. A China se saiu muito melhor do que a maioria deles.

Prima facie, portanto, para dar sentido à crise de covid-I9, o quadro teórico de Sen precisa ser substituído ou suplementado por alternativas mais apropriadas. Um candidato possível é Hirschman (1970), com seu quadro "saída, voz e lealdade", dentro do qual Sen pode ser contextualizado. Como será exposto mais adiante neste artigo, transparência de informação e competição política possuem uma importância central para as opções de "saída" e "voz", mas são inadequadas para a opção "lealdade". Ainda assim, a natureza do combate à crise epidêmica é tal que exige principalmente a opção "lealdade", em que aquisição de conhecimento e cooperação política são essenciais.

Este artigo procura oferecer uma análise comparativa das experiências da China e dos Estados Unidos com a crise epidêmica. Entende-se que, em vista das experiências de ambos os países, a tese da competição-transparência é posta em questão. No nível da governança, a aquisição de conhecimento é mais crucial que a transparência de informação. No nível da política, a cooperação é mais crucial que a competição. Sendo esse o caso, a performance comparativa da China em face dos Estados Unidos durante a crise epidêmica parece ter exposto a falha fundamental da frequentemente citada dicotomia "democracia (liberal) versus autoritarismo" para se entender a política do mundo real. Ela aponta para a necessidade de explorar alternativas que levem em consideração não apenas a forma, mas também o conteúdo da democracia, em termos de responsabilidade e representatividade dos sistemas políticos para com o povo.

\section{EM BUSCA DE UM QQUADRO TEÓRICO APROPRIADO}

No que concerne a políticas para calamidades como a covid-I9, a dicotomia "democracia versus autoritarismo" se provou tão influente que é quase hegemônica. 
Sen (1989) cunha seu famoso comentário a respeito da fome durante o "Grande Salto Adiante" chinês, do início dos anos I960, da seguinte forma: "Essa falha tem certamente uma forte relação com a ausência de uma imprensa relativamente livre e de partidos de oposição livres para criticar e responsabilizar o governo no poder." Em um tom ainda mais assertivo, Sen (1999) argumenta ainda que "na terrível história das fomes no mundo, nenhuma fome substancial já ocorreu em algum país independente e democrático com uma imprensa relativamente livre”.

Analiticamente, o argumento de Sen é feito de dois pontos. Primeiro, falta de transparência de informação na governança restringe a capacidade das instituições políticas de lidar com calamidades. Segundo, a falta de competição na política diminui o incentivo. Nos dois níveis, o argumento depende da presunção de que a informação exista independentemente dos atores. O que causa problemas é a negligência, ou mesmo a supressão, da informação essencial pelos atores em atuação.

O quadro de Hirschman, da "saída, voz e lealdade", parece ser mais abrangente e, portanto, menos dependente dessa presunção. A "saída" compreende relações de troca puras, que são acessíveis e podem ser iniciadas ou encerradas a qualquer momento pela vontade dos atores. A premissa dessas relações é que o produto trocado é bem definido e claro para os dois lados, ou seja, com total transparência de informações. A "voz" e a "lealdade" compreendem relações de longo prazo, que são necessárias se o produto em questão for de natureza idiossincrática. Entretanto, existe uma diferença sutil entre essas duas últimas opções. Os relacionamentos da "voz" ainda são uma troca competitiva. Eles são necessários para proteger a troca em condições nas quais a incompletude ou a assimetria da informação poderiam comprometer a troca. As relações de "lealdade" implicam que o problema na definição do produto seja a falta de conhecimento, e não de informação. A informação existe objetivamente, enquanto o conhecimento é o resultado da aquisição através do aprendizado - e aprendizado por esforços coletivos. Sendo assim, a cooperação, em vez da competição, é necessária para se conseguirem os resultados desejáveis.

No que diz respeito às políticas contra a covid-I9, o "produto" se refere às ações lideradas pelo Estado para combater a crise. Essas ações confrontam necessariamente incertezas que são de deficiência de conhecimento, dado o fato de que a epidemia - seus mecanismos de transmissão, seu impacto em diferentes grupos de pessoas, suas taxas de transmissão e mortalidade etc. - era principalmente uma "desconhecida inesperada" no surto inicial, e desde então permanece, na melhor das hipóteses, uma "quase conhecida inesperada". Para combater efetivamente a epidemia, é necessário interação cooperativa e ativa entre diversos atores e, finalmente, entre o Estado e o povo.

Teoricamente, a democracia liberal se centra na política competitiva. Com uma vigilância vinda de baixo devido à competição, a democracia liberal tende a ser associada com sistemas de "duplas frouxas". O autoritarismo, em contraste, tende a ser associado com sistemas de "duplas firmes", em que subunidades dos sistemas são 
"conectadas e coordenadas pela mesma cadeia de comando" (ZHOU, 2020). Zhou (2020) sugere que a inclinação da democracia liberal para politizar a governança pública é limitada. Esforços liderados pelo Estado, como os relacionados ao combate a epidemia, provavelmente seguirão a lógica do profissionalismo, e não a da política. Em contraste, o (quase) autoritarismo ao estilo chinês inclina-se intrinsecamente à politização. Uma vigilância vinda de cima é a norma para as diferentes partes de seu sistema político. Desejos políticos tendem a substituir ou superar o profissionalismo.

Independentemente de sua exposição no nível teórico, a caracterização que Zhou faz da política chinesa como um (quase) autoritarismo é convencional e ao mesmo tempo controversa. Bell (2015) prefere representar o "modelo chinês" como uma "meritocracia no topo, experimentação no meio e democracia embaixo". Embora essa representação possua elementos verdadeiros, as dinâmicas da política chinesa em face da epidemia podem ser vistas sob uma luz diferente. O mais importante é que a crise de covid-ı9 é um desafio sistêmico, e lidar com ele requer politização de um tipo particular - determinação política no topo e ativismo de toda a sociedade embaixo. Em comparação, no caso dos Estados Unidos há uma politização de outro tipo. No topo, a determinação política parece ser insuficiente para combater a epidemia porque a meritocracia foi suplantada pela engenharia eleitoral. Embaixo, o ativismo da sociedade também é insuficiente para o combate à epidemia por conta de diversos fatores, que incluem o fato de que pessoas pobres e vulneráveis têm de aguentar o fardo econômico da epidemia e, portanto, nem todas estão livres para escolher. Essas diferenças de politização nos dois países podem ter resultado, em medida significativa, na performance diversa que tiveram no combate à epidemia.

\section{GOVERNANCA E RESPOSTA À COVID-19: 0 “MODELO FIRME” CHINÊS}

\section{I. O que é o modelo firme?}

Ao se avaliar todo o pacote de políticas que o governo chinês vem usando desde que a covid-ı surgiu na província de Hubei, não é difícil verificar que ele é mais rígido que o da maioria dos outros países. Na medida em que se necessita de rastreamento de contatos e distanciamento social, surge uma questão imediata, que diz respeito a liberdades individuais e privacidade. É especialmente nesse sentido que a resposta da China à epidemia, que teve a forma muito dura de lockdowns amplos, foi severamente criticada. Compreensivelmente, durante esse processo aconteceram vários casos de excesso na conduta de oficiais locais e seus assistentes, o que causou ressentimento nas pessoas afetadas. Ainda assim, no geral, não parece ter emergido nenhum sentimento anti-Estado ou anti-establishment em uma escala significativa.

Dado que o coronavírus era, na melhor das hipóteses, um "quase conhecido", a forma mais rígida de distanciamento social foi adotada para obstruir a fonte da infecção: o lockdown em um número cada vez maior de cidades, começando com 
Wuhan no dia 23 de janeiro de 2020, e, subsequentemente, em toda a China urbana, o que obrigou todos os cidadãos a ficar a maior parte do tempo em casa. O lockdown durou mais de dois meses em grandes cidades da China, com Wuhan sendo a última cidade liberada do lockdown.

Para rastreamento de contato e distanciamento social, as autoridades locais, até o nível mais baixo, de bairros urbanos ou vilas suburbanas, foram mobilizadas para fiscalizar a implementação. Com as inspeções de líderes do topo na área crítica, o espírito de suas reuniões e discursos foi amplamente disseminado pela mídia, junto com a veiculação ininterrupta de relatórios de atualização sobre as infecções em todo o país. Conter a epidemia logo se tornou uma prioridade política, em vez de uma simples questão profissional de saúde pública. Sob essa luz, não apenas trabalhadores-chave da linha de frente, mas também burocratas até o nível de base viram isso como uma batalha que eles não podiam se dar ao luxo de perder, particularmente nos casos "superinfecciosos" e de pessoas que voltaram do exterior para a China. Mas o rastreamento parece ter ido longe demais em vários casos. Os nomes completos das pessoas não eram revelados, mas seus sobrenomes, endereços residenciais e locais de trabalho, além dos lugares em que tinham estado nos dias anteriores, foram todos dados tornados públicos.

\subsection{Estruturas de governança centralizadas e orientadas por profissionalismo}

Uma vez que a epidemia, embora ainda uma "quase conhecida", se tornou esperada, a liderança estatal chinesa formou a Força-Tarefa de Coordenação Epidêmica (apenas força-tarefa, daqui para a frente). No dia 25 de janeiro, a força-tarefa teve uma reunião para mobilizar a campanha nacional de prevenção e controle epidêmico e para ordenar aos governos locais que formassem grupos de trabalho para garantir a implementação da política. Desde então, conter a epidemia se tornou um objetivo unânime e uma prioridade política para o Estado como um todo. Esse objetivo foi concretizado em forma de tarefas específicas alocadas para autoridades de nível baixo, incluindo governos locais, empresas estatais (EEs) e todas as outras instituições públicas. 
Com esse objetivo consistente para todo o país, medidas políticas drásticas na forma de lockdowns totais puderam ser rapidamente aplicadas pelo sistema. Daí se seguiu todo tipo de esforço estatal para conter a epidemia e mitigar as consequências econômicas e os impactos adversos na vida das pessoas. Em Wuhan, o primeiro e mais seriamente atingido centro epidêmico, os recursos médicos e a capacidade hospitalar ficaram sobrecarregados. Com a mobilização vinda de cima, do governo central, garantiu-se uma mobilização nacional de recursos de saúde e logística para ajudar Wuhan. EEs receberam a ordem de expandir a produção e fornecimento de equipamentos de proteção para o pessoal da saúde e os cidadãos comuns. Além disso, hospitais especializados no atendimento a pacientes críticos e cabines hospitalares móveis para o número muito maior de pacientes não críticos foram também rapidamente construídos pelas EEs.

O profissionalismo foi outra chave para garantir a efetividade ao se lidar com a epidemia. Especialistas tiveram papel vital na tomada de decisões. Antes que a força-tarefa central fosse formada, os renomados epidemiologistas Zhong Nanshan e Li Lanjuan foram convidados para a reunião executiva do Conselho de Estado como consultores especiais. Suas recomendações profissionais foram incorporadas na mobilização nacional e nas implementações de política local. Ao receber conselho profissional, o rastreamento de contatos e o distanciamento social foram extremamente rígidos para garantir que nenhum caso suspeito pudesse escapar do radar do sistema. De forma similar, uma ampla escala de testes foi feita para mitigar as infecções causadas pelos pacientes assintomáticos.

Não há dúvidas de que a contenção bem-sucedida da epidemia na China foi conseguida principalmente pela cooperação dos vários agentes, incluindo o governo de cima a baixo, empresas e todos os cidadãos comuns. Contudo, a estrutura centralizada de governança teve problemas intrínsecos ao encarar a "desconhecida inesperada". Tendo de prestar contas para cima, as autoridades locais tiveram a tendência de ignorar ou mesmo suprimir as "vozes" da base porque pretendiam minimizar seus erros ou inações, resolvendo, diminuindo ou mesmo encobrindo os problemas para evitar consequências políticas. Isso de fato aconteceu em Wuhan no estágio inicial do surto.

No período crítico entre 6 e I7 de janeiro de 2020, anúncios da Comissão $\mathrm{Mu}$ nicipal de Saúde de Wuhan afirmaram repetidamente que nenhum novo caso havia sido encontrado, o que não correspondia à situação verdadeira. Foi precisamente durante esse período que o município de Wuhan e a província de Hubei tiveram as sessões anuais de seus respectivos Congresso Popular e Conferência de Consulta Política Popular. Inevitavelmente, essa coincidência levou à suspeita de acobertamentos deliberados por parte das autoridades locais, no intuito de dar bom andamento a suas atividades políticas.

Na medida em que isso indica alguns problemas de inadequação ao lidar com a epidemia no primeiro estágio, quando o vírus ainda era uma "desconhecido inespe- 
rado", a falha deve ser atribuída ao princípio de uma prestação de contas para cima, que rege o funcionamento da Comissão Nacional de Saúde e as autoridades locais. Em outras palavras, a falha se deveu muito mais às instituições que aos agentes. No entanto, a meritocracia garantiu um autoaperfeiçoamento e autocorreção. Quando o atraso e o acobertamento no primeiro estágio foram descobertos em Wuhan, dois importantes líderes da província de Hubei e da prefeitura de Wuhan foram removidos de suas posições. Eles foram responsabilizados como os principais líderes (yibashou) da área crítica por causa de sua inação no primeiro estágio. $O$ plano de remediação tinha também a função de alertar uma gama maior de burocratas de todos os níveis de que suas vidas políticas estariam em risco se se descobrissem "disfunções ou maus comportamentos". Por sua vez, o plano reforçou a implementação do "modelo duro".

\section{GOVERNANÇA E RESPOSTA À COVID-19: 0 "MODELO FROUXO" ESTADUNIDENSE}

\section{I. O que é o modelo frouxo?}

Até aqui os Estados Unidos parecem não ter explorado um pacote de medidas de resgate efetivo, que responda à sua condição. Suas iniciativas de contenção da epidemia são muito mais frouxas que as da China. Um dos motivos é que, diferentemente do Estado chinês, que colocou o controle da epidemia como sua primeira e principal prioridade política, os Estados Unidos a tratam como só um entre muitos objetivos - e nem sequer o mais importante. Outro motivo é que o sistema político descentralizado dos Estados Unidos simplesmente não permite a operação do modelo duro, ao estilo chinês, por causa da falta de cooperação e de consistência entre os governos federal e estaduais. A "reabertura" precoce da economia em maio é um sinal claro desse "modelo frouxo". Em contraste com a curva em formato de sino que representa a evolução da escalada da epidemia na China durante o período de mais ou menos dois meses, a curva dos Estados Unidos tende a continuar subindo depois de mais de três meses. De forma chocante, no início de outubro, até a Casa Branca se tornou um epicentro.

O rastreamento de contatos tem sido raro, já que ele inevitavelmente infringe a privacidade individual. Nesse caso, a intervenção governamental fez pender a balança para o lado dos direitos individuais muito mais que para o dos valores coletivos. $\mathrm{E}$ testes não foram feitos em uma escala grande o suficiente. Quando os Estados Unidos precisaram urgentemente de uma capacidade maior de testes, em maio, o presidente Trump reclamou repetidas vezes e questionou a necessidade de testes em larga escala, comentando: "Se não fizéssemos testes, teríamos poucos casos" (BLAKE, 2020). Quando o estado de emergência nacional foi declarado pelo governo federal no dia I3 de março, alguns governos estaduais (Califórnia, Flórida, Arizona etc.) já haviam declarado emergência muito tempo atrás. O presidente queria reabrir a economia muito antes que a situação em si permitisse. Muitas pessoas se ressentiram das políticas de 


\section{A questão é: até que ponto a falha de Trump, o representante das instituições políticas estadunidenses, reflete a falha das instituições em si? Ou: por que as instituições perderam sua capacidade de corrigir o mau comportamento de seu mandatário?}

distanciamento social e de medidas semelhantes de contenção do vírus e saíram às ruas para pressionar os governos estaduais a reabrir a economia. Em resposta, o presidente tuitou, em maiúsculas: "LIBERTEM MINNESOTA", "LIBERTEM MICHIGAN" e "LIBERTEM A VIRGÍNIA e salvem sua ótima 2a emenda. Ela está sitiada”.

\subsection{Estruturas de governança descentralizadas}

Não deve haver dúvidas de que o erro ao lidar com a epidemia é do governo Trump. A questão é: até que ponto a falha de Trump, o representante das instituições políticas estadunidenses, reflete a falha das instituições em si? Ou: por que as instituições perderam sua capacidade de corrigir o mau comportamento de seu mandatário? O sistema federalista dos Estados Unidos garante a divisão de poder entre os governos federal e estaduais, mas, ao mesmo tempo, pode resultar em uma falta de cooperação entre as instâncias. Quando "disfunções ou maus comportamentos" e campanha pela reeleição ocorrem simultaneamente, o sistema da democracia liberal pode perder sua capacidade de autocorreção se "considerações políticas de curto prazo que impactam em chances de reeleeição" forem priorizadas (BELL, 20I5, p. I72-I73).

Uma característica fundamental do federalismo de tipo estadunidense é a alta autonomia dos governos estaduais. Ao lidar com um "conhecido esperado", pode ser um bom sistema, no qual o governo estadual se reserva o direito de personalizar suas políticas de acordo com seu quadro legal e condições específicas. Ao encarar uma "desconhecida inesperada", ainda é possível ter a vantagem de preservar a transparência das informações, já que o governo estadual não tem razões para encobrir ou esconder fatos. No entanto, a falta de consistência das políticas em diferentes estados e a falta de coordenação do governo federal tendem a causar ineficiências. As des- 
vantagens do federalismo de tipo estadunidense são mais significativas ao se encarar a "desconhecida inesperada". Outro fator que aumenta as dificuldades de cooperação política é a competição política interpartidária. Dado o poder já insuficiente tanto do governo estadual quanto do governo federal, priorizar interesses partidários e considerações sobre a reeleição sabota a cooperação. Diante disso, não é surpresa observar que, quando as equipes médicas insistiram para que o governo oferecesse ajuda em equipamento de proteção individual (EPI), o presidente Trump tenha até chamado a falta de EPI em Nova York (tradicionalmente um estado dominado pelos democratas) de fake news.

Para conter a epidemia é necessário que a nação aja de forma forte e consistente como um todo, inclusive impondo certas restrições às atividades pessoais. É também necessário que a nação mobilize prontamente profissionais e recursos para áreas críticas. Em vez de formas de lockdown nacional e mobilização de recursos, houve respostas fraturadas e até mesmo políticas contraditórias implementadas por cada estado. Em vez de tranquilizar as pessoas e apoiar os governadores, o governo federal contradisse e sabotou a autoridade dos governos locais e emitiu informações desencontradas para as pessoas, tornando ainda mais confuso o que já era um "modelo frouxo". Na verdade, nenhuma das instituições federais - o Ministério da Saúde e Serviços Humanos, a Agência Federal de Gerenciamento de Emergência, os Centros de Controle e Prevenção de Doenças etc. - tem poder suficiente para ordenar às autoridades locais que executem ações conjuntas.

Em contraste com as estruturas de poder centralizadas da China, as estruturas descentralizadas dos Estados Unidos podem ter causado sérios atrasos nas ações e minado o profissionalismo. Persistentemente durante a epidemia, o presidente deu recomendações médicas errôneas, como injetar desinfetante e tomar hidroxicloroquina, ignorando conselhos médicos profissionais. $\mathrm{O}$ presidente exerceu o poder indicando ou removendo membros de sua equipe administrativa e deixando profissionais de lado (LUCE, 2020). Em vez de aceitar os conselhos da Organização Mundial da Saúde (OMS), o governo Trump acusou-a sem provas de ter sido sequestrada pela China, e anunciou que os Estados Unidos sairiam da organização.

Diante de qualquer "disfunção ou mau comportamento" dos agentes das instituições, a capacidade corretiva da democracia liberal é tipicamente realizada por pessoas que elegem um novo 
candidato à Presidência para então formar uma nova administração na esperança de reparar o erro. No caso da covid-I9, tal recuperação é seriamente necessária. Ainda assim, não há certeza de que isso vá acontecer. Não há sinal de forças políticas fortes o suficiente para responsabilizar Trump pela falha em lidar com a crise epidêmica. Não há sequer certeza de que ele será substituído por um político mais responsável, ou ao menos razoavelmente funcional, após as eleições.

Está claro que o presidente incluiu a crise epidêmica como parte de sua estratégia de reeleição. Quando os Estados Unidos começaram a lidar com o surto doméstico em março, a epidemia já havia se tornado "esperada" e pelo menos uma "quase conhecida". O governo federal fez poucos esforços para se preparar para combatê-la. Em vez disso, gastou tempo valioso, de janeiro a março, politizando-a. O principal projeto do governo Trump foi culpar os outros e fazer seu povo desviar a atenção dos erros cometidos ao atacar a China. Sem qualquer evidência da origem do vírus, o presidente Trump seguia se referindo a ele como "o vírus de Wuhan" e/ou "o vírus chinês" para despertar o ódio à China.

\section{REFLEXÃO: DA GOVERNANÇA À POLÍTICA ECONÔMICA}

Nos primeiros meses da covid-I9, o termo momento Chernobyl da China estava na moda entre comentaristas e políticos. No final de abril, quando o número de infecções tanto na União Europeia quanto nos Estados Unidos tinha passado de I milhão, esse termo pareceu perder completamente o valor. Em seu lugar entrou outro, relacionado aos soviéticos: momento Sputinik da China. Este último termo demonstra a aceitação, relutante, da performance superior da China, enquanto também alerta que celebrar essa superioridade é prematuro (MILANOVIC, 2020).

Essa alegação de precocidade é tanto política quanto intelectualmente motivada. Ela é profundamente enraizada na dicotomia "democracia liberal versus autoritarismo". O filósofo Fukuyama (2020) afirma: "É errado sustentar a abordagem totalitária do PCCh [Partido Comunista da China] ao lidar com o vírus como um modelo a ser emulado por outros países." De forma semelhante, o economista Acemoglu (2020) apresenta um preocupante cenário, da "China leve", que poderia se tornar realidade no Ocidente: "Em tempos de incerteza profunda, quando há necessidade de uma coordenação de alto nível e liderança, o primeiro instinto de muitas pessoas é se voltar mais uma vez para soluções hobbesianas." Em um tom mais intelectual, o economista Milanovic (2020) afirma: "O momento Sputnik da União Soviética se mostrou passageiro, assim como pode acontecer com o da China, se o outro lado [os EUA] escolher usar suas vantagens significativas, como a flexibilidade na tomada de decisões, a responsabilidade dos governos locais e a transparência."

Para avaliar essas afirmações, é necessário voltar à exposição dos diferentes quadros teóricos de Amartya Sen e Albert Hirschman. A crítica a respeito da transparência de informações, baseada implícita ou explicitamente na opção "voz", pare- 
ce ter elementos de verdade, dados os erros iniciais das autoridades locais e/ou dos profissionais da Comissão Nacional de Saúde citados acima. Ainda assim, esses elementos não podem ser a verdade principal, já que os críticos ignoram claramente a "inesperada e desconhecida" natureza da epidemia em seu surto inicial.

Mais importante, ao passar a culpa de estruturas de governança para o sistema político, os críticos encontram dificuldade de explicar o sucesso subsequente da China em conter a epidemia. Os já citados estudiosos parecem compartilhar a mesma visão ao caracterizar o sistema chinês meramente como "autoritário". Eles tendem a perceber as medidas drásticas que contiveram de forma bem-sucedida a epidemia - mobilização de recursos, testagem ampla, rastreamento universal, lockdowns totais etc. - como imposição das autoridades sobre as pessoas. Em contraste, acadêmicos da Nova Esquerda chinesa, como Wang Hui (OWNBY, 2020) e Wei Nanzhi (WEI, 2020), argumentam que os esforços da China para combater a epidemia de coronavírus na verdade envolveram a cooperação ativa entre Estado e povo. Sem essa cooperação, as medidas drásticas iniciadas pelo Estado não teriam sido efetivamente implementadas, muito menos teriam alcançado seus objetivos. Diz-se que a tradição revolucionária da "guerra popular" está em ação.

Milanovic, se atendo à dicotomia "democracia liberal versus autoritarismo", chegou à conclusão oposta. Ao elogiar a "flexibilidade" das estruturas de governança e do sistema político básico dos EUA, ele parece acreditar que a opção da "saída" é provavelmente melhor para combater a epidemia. Conceitualmente, a "saída", ou relações de mercado, é caracterizada por flexibilidade, em oposição à rigidez das relações de longo prazo da "voz" e da "lealdade". Em face da epidemia como existência objetiva que implica consequências compulsórias para os indivíduos, em vez de um bem ou serviço ordinário que os indivíduos são livres para escolher, a flexibilidade pode ser uma desvantagem mais do que uma vantagem. Ela exige medidas compulsórias sustentadas por relacionamentos de longo prazo entre o Estado e o povo, e, na verdade, uma cooperação ativa entre os dois lados para lidar com a epidemia como uma "quase conhecida".

O que aconteceu realmente nos Estados Unidos foi a predominância das opções de "saída" exercitadas tanto pelo Estado quanto pelos indivíduos nos esforços de combate à epidemia. As ações dos governos Federal e estaduais estiveram longe de ser adequadas, enquanto o público em geral esteve longe de ser cooperativo. Os protestos anti-lockdown em maio foram demonstrações vívidas de abandono dos esforços. Os protestos antirracistas de junho inevitavelmente tiveram efeitos adversos nesses projetos. Ambos os tipos de protesto provavelmente se relacionaram com o fato de que as pessoas pobres e vulneráveis na sociedade estadunidense foram forçadas a carregar os principais fardos da crise epidêmica. No final, tanto o Estado quanto os indivíduos pareceram desistir. Os Estados Unidos parecem seguir na direção de uma peculiar "imunidade de rebanho", sem que se saiba quando as vacinas irão aparecer e que mutações o coronavírus sofrerá. 


\section{Os esforços da China para combater} a epidemia de coronavírus na verdade envolveram a cooperação ativa entre Estado e povo. Sem essa cooperação, as medidas drásticas iniciadas pelo Estado não teriam sido efetivamente implementadas, muito menos teriam alcançado seus objetivos. Dizse que a tradição revolucionária da "guerra popular" está em ação

Temendo que as democracias liberais estejam perdendo para o autoritarismo na crise do coronavírus, Fukuyama (2020) faz o seguinte apelo: "Antes de pensar em mudar a China, nós precisamos mudar os Estados Unidos e tentar restaurar sua posição como exemplo global dos valores democráticos liberais ao redor do mundo." Mas como conseguir isso?

O cientista político Stasavage (2020) parece oferecer uma resposta: "Existem diversos caminhos que podemos tomar em resposta a essa crise, e apenas um deles é desejável - fortalecer o Governo Federal, primeiro fazendo investimentos para reduzir a desconfiança entre os cidadãos". Essa resposta indica o reconhecimento da importância do conteúdo do sistema político, ou seja, o relacionamento entre Estado e povo, em vez do foco apenas em sua forma. O insight intelectual da dicotomia "democracia versus autoritarismo" é fortemente limitado nesse quesito.

Quaisquer que sejam precisamente os atributos de um relacionamento desejável entre povo e Estado, a confiança está no centro dele. Sob essa luz parece claro que, no combate à crise da covid-I9, a interação entre Estado e povo formou um círculo virtuoso na China, enquanto nos Estados Unidos se formou um círculo vicioso. Na ideologia oficial da República Popular da China, seu sistema político-econômico é chamado de "ditadura democrática popular". A ênfase é no conteúdo, e não na forma do sistema. O "conteúdo" se refere à responsabilidade e representatividade do Estado para com o povo. Afirma-se que esse sistema, com uniformidade de interesses entre Estado e povo, é superior ao seu sistema alternativo, ou rival, da "ditadura democrática da burguesia", caracterizada pelo antagonismo entre povo e Estado. Essa afirmação é sustentada pela máxima leninista de que a "democracia burguesa" é afinal ainda uma "ditadura burguesa". Ela se assenta como rival da dicotomia "democracia liberal versus autoritarismo". Ambas as formulações, em certo sentido, estão sujeitas ao teste nesta (ainda em curso) crise epidêmica. 


\section{CONCLUSÕES}

Por sua natureza peculiar como desafio sistêmico, o controle da crise de covid-I9 exige ações rápidas e fortes. Parece que a China empregou um "modelo firme", enquanto as medidas erráticas dos EUA formaram um "modelo frouxo". Este artigo tentou caracterizar e examinar os dois modelos pela perspectiva das estruturas de governança e das capacidades corretivas das duas diferentes instituições políticas.

As estruturas do governo chinês são caracterizadas por uma prestação de contas para cima, e isso poderia facilmente causar erros em relação ao "desconhecido inesperado". Porém, com a meritocracia como princípio orientador e a cooperação como sua funcionalidade principal, o sistema político chinês também parece capaz de corrigir rapidamente seus erros, particularmente quando a epidemia se torna "esperada". Em comparação, as estruturas do governo estadunidense são caracterizadas pela prestação de contas para baixo. Isso é uma vantagem ao evitar erros quando se confronta com o "desconhecido inesperado". Ainda assim, com a competição - e a engenharia eleitoral de 2020 - tanto como princípio orientador quanto como sua funcionalidade, o sistema político estadunidense parece ter certa deficiência em lidar com a crise epidêmica.

No final, os padrões contrastantes da politização da governança nos dois países têm suas raízes nos respectivos relacionamentos entre povo e Estado. Existem formas rivais de conceituar essas relações: o Estado chinês argumenta que é a da "democracia popular versus democracia burguesa", enquanto a visão dominante entre comentaristas ocidentais é a da "democracia liberal versus autoritarismo". Ambas estão sendo testadas na crise pandêmica de 2020.

* Dic Lo é leitor de Economia na Faculdade de Estudos Orientais e Africanos (SOAS) da Universidade de Londres.

** Yuning Shi é doutoranda em economia na SOAS.

Os autores agradecem a Thanos Moraitis, Xinwen Zhang, Di Fang, Longcan Zou, Jiaxing Li e Huangnan Shen, por sua ajuda na pesquisa desse trabalho.

Artigo original publicado no Canadian Journal of Development Studies, v. 41, n 4, em 12 de novembro de 2020. Disponível em: <https://doi.org/10.1080/02255189.2020.18 39393>.

Tradução: Isadora Sinay.

Texto recebido em setembro de 2020; aprovado em setembro de 2020. 
ACEMOGLU, Daron. The post covid state. Project Syndicate, 5 jun. 2020. Disponível em: <www.project-syndicate.org/onpoint/four-possible-trajectories-after-covid19-daron-acemoglu-2020-06?utm_ source $=$ facebook\&utm_medium =organic-social\&utm_campaign=page-posts-june20\&utm_posttype $=$ link\&utm_format $=16 \% 3$ A9\&utm_creative $=$ quote-card\&utm_post-date $=2020-06-05 \& f b c l i d=1-$ wAROCiWr_YqoZqQkJlptf7BdHIzRtM6U24I0xERIc6Lo02JqetXvRmZyvFcg>. Acesso em: 22 nov. 2020.

BELL, Daniel A. The China model: political meritocracy and the limits of democracy. Princeton: Princeton University Press, 2015.

BLAKE, Aaron. Trump's continually strange comments on possibly "overrated" coronavirus testing. The Washington Post, Washington, D.C., 15 maio 2020. Disponível em: <www.washingtonpost.com/ politics/2020/05/15/trumps-thoroughly-strange-commentary-coronavirus-testing>. Acesso em: 22 nov. 2020.

FUKUYAMA, Francis. What kind of regime does China have?. The American Interest, v. 15, n. 6, 18 maio 2020. Disponível em: <www.the-american-interest.com/2020/05/18/what-kind-of-regime-doeschina-have>. Acesso em: 22 nov. 2020.

HIRSCHMAN, Albert O. Exit, voice, and loyalty: responses to decline in firms, organizations, and states. Cambridge: Harvard University Press, 1970.

LUCE, Edward. Inside Trump's coronavirus meltdown. Financial Times, Londres, 14 maio 2020. Disponível em: <www.ft.com/content/97dc7de6-940b-11ea-abcd-371e24b679ed>. Acesso em: 22 nov. 2020.

MILANOVIC, Branko. Is the pandemic China's Sputnik moment?: what a virus reaveals about two systems. Foreign Affairs, Nova York, 12 maio 2020. Disponível em: <www.foreignaffairs.com/articles/ united-states/2020-05-12/pandemic-chinas-sputnik-moment>. Acesso em: 22 nov. 2020.

OWNBY, David. Wang Hui, "revolutionary personality". Reading the Chine Dream. 2020. Disponível $\mathrm{em}$ : <www.readingthechinadream.com/wang-hui-revolutionary-personality.html>. Acesso em: $22 \mathrm{nov}$. 2020.

SEN, Amartya. Democracy as a universal value. Journal of Democracy, v. 10, n. 3, p. 3-17, 1999. Disponível em: <www.unicef.org/socialpolicy/files/Democracy_as_a_Universal_Value.pdf>. Acesso em: 22 nov. 2020.

Food and freedom. World Development, v. 17, n. 6, p. 769-781, 1989. Disponível em: <https://doi.org/10.1016/0305-750X(89)90001-6>. Acesso em: 22 nov. 2020.

STASAVAGE, David. Covid-19 has exposed the weakness of America's federal government. CNN, Atlanta, 1 jul. 2020. Disponível em: <https://edition.cnn.com/2020/07/01/opinions/covid-19-america-federal-government-stasavage/index.html?fbclid=IwAR02O5AKO4gw1DKHShFxhd0EVd6SygsJDtWISWrTkqYn2oTUopoYTcYsn5s>. Acesso em: 22 nov. 2020.

WEI, Nanzhi. 2020. Procedure justice alone cannot satisfy the Chinese people, and the Communist Party clearly knows this. The Observers [Guanchazhe], 4 jul. 2020. Disponível em: <www.guancha. cn/weinanzhi/2020_07_04_556292.shtml>. Acesso em: 22 nov. 2020.

ZHOU, Xueguang. Organizational response to covid-19 crisis: reflections on the Chinese bureaucracy and its resilience. Management and Organization Review, v. 16, n. 3, p. 473-484, jul. 2020. Disponível em: <https://doi.org/10.1017/mor.2020.29>. Acesso em: 22 nov. 2020. 